Bond University

Research Repository

\title{
Use of the booklet category test to assess abstract concept formation in schizophrenic disorders
}

Steindl, Stanley R.; Boyle, Gregory J.

Published in:

Psychological Assessment

Licence:

Other

Link to output in Bond University research repository.

Recommended citation(APA):

Steindl, S. R., \& Boyle, G. J. (2012). Use of the booklet category test to assess abstract concept formation in schizophrenic disorders. In Psychological Assessment (1 ed., Vol. 1-4, pp. 183-188). SAGE Publications Ltd.

\section{General rights}

Copyright and moral rights for the publications made accessible in the public portal are retained by the authors and/or other copyright owners and it is a condition of accessing publications that users recognise and abide by the legal requirements associated with these rights.

For more information, or if you believe that this document breaches copyright, please contact the Bond University research repository coordinator. 


\section{Bond University}

\section{ePublications@bond}

$1-1-2012$

\section{Use of the Booklet Category Test to assess abstract concept formation in schizophrenic disorders}

Stanley R. Steindl

University of Queensland

GregoryJ. Boyle

Bond University, Gregory_Boyle@bond.edu.au

Follow this and additional works at: http://epublications.bond.edu.au/hss_pubs

Part of the Arts and Humanities Commons, and the Psychology Commons

\section{Recommended Citation}

Steindl, Stanley R. and Boyle, Gregory J., "Use of the Booklet Category Test to assess abstract concept formation in schizophrenic disorders" (2012). Humanities \& Social Sciences papers. Paper 701.

http://epublications.bond.edu.au/hss_pubs/701 
Use of the Booklet Category Test to Assess Abstract Concept Formation in Schizophrenic Disorders

\author{
Stanley R. Steindl
}

Department of Psychology, University of Queensland and Gregory J. Boyle

Department of Psychology, University of Queensland School of Humanities \& Social Sciences, Bond University 


\begin{abstract}
The relationship of concept formation abilities to the presence or absence of delusions in schizophrenic disorders was investigated. Twenty-six schizophrenic patients and 14 normal individuals were administered a short form of the Booklet Category Test (BCT). Patients were grouped into those with and without delusions. It was hypothesized that the delusional group would perform significantly better on the BCT (obtain lower error scores) than the non-delusional group. Normal and delusional groups obtained significantly lower BCT error scores than the non-delusional group, even when differences in IQ scores were statistically partialled out. The two schizophrenic groups also differed significantly on BCT error scores with the delusional group performing better than the nondelusional group.
\end{abstract}


It has been reported that schizophrenic individuals tend to exhibit a deficit in abstract concept formation as measured on the Category Test (CT) or the Wisconsin Card Sorting Test (WCST; Heaton, Baade, \& Johnson, 1978; Morice, 1990; Wright, 1975). When responding to the WCST, regional cerebral blood flow (rCBF) significantly distinguished schizophrenic individuals from controls (Weinberger, Berman, \& Zec, 1986). Normals showed an increase of rCBF in the dorsolateral prefrontal cortex (DLPFC) whereas schizophrenics showed none. Liddle and Morris (1991) reported that frontal lobe impairment correlated with severity of psychomotor poverty and disorganisation. Crow (1980) reported that individuals with Type I (positive) symptoms exhibited significantly less intellectual impairment as compared with patients with Type II (negative) symptoms (cf. Hoff, Riordan, O'Donnell, Morris, \& De Lisi, 1992). Weinberger (1987) suggested that negative symptoms may be related to frontal lobe dysfunction, particularly in the DLPFC.

The Booklet Category Test (BCT; DeFilippis \& McCampbell, 1979) measures abstract concept formation (Boyle, 1988a, 1988b; Hammeke, 1985; Heaton \& Pendleton, 1981). Based on attempts at shortening the CT (Boyle, 1975, 1986), an abbreviated BCT would seem suitable for use with schizophrenic patients (cf. Reitan \& Davidson, 1974). Russell and Levy (1987) also devised a short-form comprising 95 items. In the present study, their procedure is used to shorten the BCT.

The purpose of this study is to examine abstract concept formation in schizophrenics, in relation to the presence or absence of delusional symptoms. It is hypothesized that there is a continuum of deficits on the BCT going from controls, to recently delusional schizophrenic individuals, to schizophrenic patients with negative symptoms, with the deficit on the BCT increasing across the three groups respectively. 


\section{METHOD}

\section{Subjects}

Twenty-six volunteer patients satisfying the DSM III-R (APA, 1987) criteria for schizophrenia were recruited. Seventeen were current inpatients at the Wolston Park Psychiatric Hospital, Brisbane, and nine were past patients. Individuals were excluded if they had sustained any significant head injury, if they suffered from epilepsy, substance abuse, poor English skills, or were 55 years of age or older. Most patients were taking antipsychotic medication.

Presence or absence of delusional episodes was ascertained from patients' DSM III-R diagnoses, progress charts, discharge summaries, registrar reports, and patient self-reports. The two subgroups consisted of (a) those recently and presently having delusions; and (b) those who had never experienced delusions. These two schizophrenic subgroups were compared with a normal control group, comprising undergraduates and individuals • from the general adult community, among whom neurological problems had been ruled out. An attempt was made to match across groups for age and sex (Table 1).

TABLE!

Descriptive Characteristics for Each Group

\begin{tabular}{lclllrr}
\hline Group & $\begin{array}{c}\text { Number } \\
(\mathrm{M}: \mathrm{F})\end{array}$ & $\begin{array}{l}\text { Sex } \\
\text { (Years) }\end{array}$ & Age & \multicolumn{2}{c}{ BCT Error Score Mean IQ BPRS Score } \\
\hline Control & 14 & $12: 2$ & 32.5 & $16.93(10.16)$ & 113.73 & \\
Delusional & 13 & $10: 3$ & 37.1 & $31.38(14.28)$ & 94.94 & 45.77 \\
Non-delusional & 13 & $13: 0$ & 31.9 & $38.31(12.53)$ & 100.52 & 33.85 \\
\hline
\end{tabular}

Note. Significant differences in mean BCT Error Scores between groups confirmed using Scheffe tests.

\section{Instruments and Procedure}

Tests used included the Schonell Graded Word Reading Test (SGWRT; Schonell, 1942) for schizophrenic individuals, and its derivative, the National 
SGWRT IQ range from 115 up to 128). A shortened 95-item version of the BCT was administered followed by the SGWRT/NART -a measure of pre- morbid intelligence (Crawford, Stewart, Cochrane, Parker, \& Besson, 1989; Wiltshire, Kinsella, \& Prior, 1991). As well, a psychopathology scale, the Brief Psychiatric Rating Scale (BPRS; Overall \& Gorham, 1962), was administered by independent pairs of nursing staff. The BPRS provides a rapid assessment of severity of schizophrenic states on a scale ranging from 1 (symptom not pre- sent) to 7 (symptom extremely severe). Total testing time was about 30 to 45 minutes for schizophrenics, and 15 to 20 minutes for controls. To equate the error score to that of the full BCT, the final score was multi- plied by 2.2 as suggested by Russell and Levy (1987), giving a cutoff of 51 errors. Two independent variables were the presence or absence of (a) schizophrenia, and (b) delusions. Ancillary independent variables included intelligence (SGWRT/NART) and status of psychopathology (BPRS) which served as covariates to partial out possible confounding variance (cf. Adams, Brown, \& Grant, 1985). Scores on the SGWRT/NART were translated into equivalent WAIS Full Scale IQ scores using an empirically validated algorithm.

\section{RESULTS}

Means and standard deviations of the key variables for the control, delusion- al and non-delusional groups are presented in Table 1. Although a significant difference was found in premorbid IQ scores across all three groups, F $(2,34)=13.91, p<.001$, Scheffé tests revealed that the delusional and nondelusional groups did not differ significantly. Product-moment correlations between full-scale BCT error scores, BCT Subtests 1-6, and estimates of premorbid intelligence were calculated. Subtests 3-6 correlated significantly with the full-scale error score, ranging from .65 to .82 . Also, Subtest 4 correlated 
significantly but not as highly with Subtests 3 and 6 (.51 and .58, respectively). Subtest 3 was the most difficult for all groups followed by Subtests 5, 4, and 6 (Figure 1).

Although most subjects correctly responded to Subtests 1 and 2, the proportion of variance accounted for was very low, being $7 \%$ and $31 \%$, respectively. Premorbid intelligence estimates correlated significantly (inversely) with the full-scale BCT error score (-.55), and Subtests 3, 4, and 6. Increasing age correlated directly with full-scale BCT error-score (.48) and Subtests 4 and 5. Thus, an ANCOVA was performed on the BCT error scores of the three groups, with IQ statistically partialled out (cf. Huitema, 1980; Keppel, 1991). A significant difference was found between groups, $F(2,36)=4.56, p<.05$. Scheffé tests revealed that the control group scores were significantly different (at $p<.05)$ from those of the non-delusional group. Also a significant difference between the delusional and non-delusional groups was observed, $\mathrm{F}(3,23)=6.13, \mathrm{p}<.05$, when the BPRS scale score was included as a covariate, suggesting the delusional subgroup performed better on the BCT than did the non-delusional subgroup. 


\section{DISCUSSION}

Schizophrenic individuals as a group appear to exhibit a deficit in abstract concept formation skills compared with normal individuals. Also, the presence

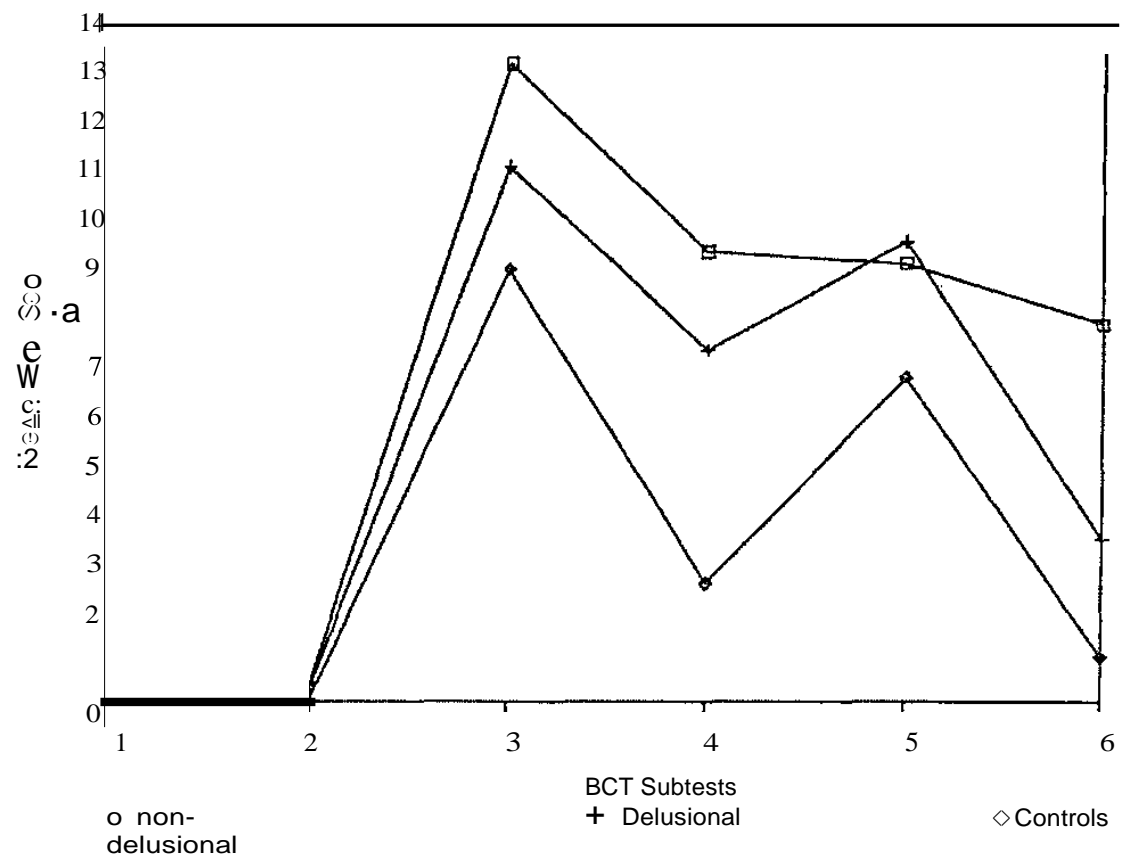

FIGURE 1. Mean error scores on each BCT Subtest for delusional, non-delusional, and control groups. 
or absence of delusions in schizophrenic patients was found to predict BCT error scores. With the effects of IQ partialled out statistically, normal controls were found to be more similar to delusional than to non-delusional schizophrenic patients, in terms of their BCT error scores. The present findings justify the conclusion that abstract thinking is more impaired in non-delusional schizophrenics than in those with delusions. The superior performance of the delusional group on the BCT over the non-delusional group may be due to brain impairment associated with negative schizophrenic symptoms (Type II), unrelated to delusions (Type I).

This study also exemplifies the double dissociation methodology in that while the delusional schizophrenics exhibited a lower mean IQ score, they performed better (obtaining lower error scores) on the shortened BCT than did the non-delusional schizophrenics, providing strong support for the major hypothesis. However, since the SGWRT/NART is a reading test, it is probably a crystallized intelligence test whereas the shortened BCT is a fluid intelligence test. Hence, the present findings also suggest an alternative hypothesis that non-delusional schizophrenics might be more impaired on fluid abilities than on prefrontal functioning, per se.

\section{CONCLUSION}

The present study provides evidence for the utility of the BCT in distinguishing between normal controls and schizophrenic patients, and further, between schizophrenics who do and do not exhibit delusional symptoms. Since most of the schizophrenic patients were taking antipsychotic medication intended to ameliorate schizophrenic symptoms, the present findings seem all the more pertinent. As suggested by Mortimer (1992, p. 296), neuropsychological tests such as the BCT may bridge the "gulf between the clinical phenomena of schizophrenia and the presumed underlying brain dysfunction." 


\section{REFERENCES}

Adams, K. M., Brown, G. G., \& Grant, I. (1985). Analysis of covariance as a remedy for demographic mismatch of research subject groups: Some sobering simulations. Journal of Clinical and Experimental Neuropsychology, 7, 445462.

APA. (1987). Diagnostic and Statistical manual of mental disorders (DSM ill-R). Washington, DC: Author.

Boyle, G. J. (1975). Shortened Halstead Category Test. Australian Psychologist, 10, 8184.

Boyle, G. J. (1986). Clinical neuropsychological assessment. Abbreviating the Halstead Category Test of brain dysfunction. Journal of Clinical Psychology, 42, 615625.

Boyle, G. J. (1988a). The Booklet Category Test of brain dysfunction. Psychological Test Bulletin, 1, 31-33.

Boyle, G. J. (1988b). What does the neuropsychological Category Test measure? Archives of Clinical Neuropsychology, 3, 69-76.

Crawford, J. R., Stewart, L. E., Cochrane, R. H. B., Parker, D. M., \& Besson, J. A. 0. (1989). Construct validity of the National Adult Reading Test: A factor analytic study. Personality and Individual Differences, 10, 585-587.

Crow, T. J. (1980). Molecular pathology of schizophrenia: More than one disease process? British Medical Journal, 280, 1-9.

DeFilipis, N. A., \& McCampbell, E. (1979). The Booklet Category Test: Research and clinical form. Odessa, FL: Psychological Assessment Resources. 
Hammeke, T. A. (1985). Review of the Booklet Category Test. In J. V. Mitchell (Ed.), The ninth mental measurements yearbook. Lincoln, NE: Buros Institute of Mental Measurements.

Heaton, R. K., Baade, L. E., \& Johnson, K. L. (1978). Neuropsychological test results associated with psychiatric disorders in adults. Psychological Bulletin, 85, 141162.

Heaton, R. K., \& Pendleton, M. G. (1981). Use of neuropsychological tests to predict adult patients everyday functioning. Journal of Consulting and Clinical Psychology, 49, 807-821. Hoff, A. L., Riordan, H., O'Donnell, D. W., Morris, L., \& De Lisi, L. E. (1992). Neuropsychological functioning of first-episode schizophreniform patients. American Journal of Psychiatry, 149, 898-903.

Huitema, B. E. (1980). The analysis of covariance and alternatives. New York: Wiley. Keppel, G. (1991). Design and analysis: A researcher's handbook. Englewood Cliffs, NJ: Prentice Hall.

Liddle, P. F., \& Morris, D. L. (1991). Schizophrenic syndromes and frontal lobe performance. British Journal of Psychiatry, 158, 340-345.

Morice, R. (1990). Cognitive inflexibility and prefrontal dysfunction in schizophrenia and mania. British Journal of Psychiatry, 157, 50-54.

Mortimer, A. M. (1992). Phenomenology: Its place in schizophrenia research. British Journal of Psychiatry, 161,293-297.

Nelson, H. E. (1982). National Adult Reading Test (NART): Test manual. Windsor, UK: NFER- Nelson.

Overall, J. E., \& Gorham, D. R. (1962). The Brief Psychiatric Rating Scale. Psychological Reports, 10, 799-812. 
Reitan, R. M., \& Davidson, L.A. (Eds.). (1974). Clinical neuropsychology: Current status and implications. New York: Wiley.

Russell, E. W., \& Levy, M. (1987). Revision of the Halstead Category Test. Journal of Consulting and Clinical Psychology, 55(6), 898-901.

Schonell, F. (1942). Backwardness in the basic subjects. London: Oliver \& Boyd.

Weinberger, D. R. (1987). Implications of normal brain development for the pathogenesis of Schizophrenia. Archives of General Psychiatry, 44, 660-669.

Weinberger, D. R., Berman, K. F., \& Zec, R. F. (1986). Physiologic dysfunction of dorsolateral prefrontal cortex in schizophrenia. Archives of General Psychiatry, 43, 114-124.

Willshire, D., Kinsella, G., \& Prior, M. (1991). Estimating WAlS-R IQ from the National Adult Reading Test A cross-validation. Journal of Clinical and Experimental Neuropsychology, 13, 204-216.

Wright, D. M. (1975). Impairment in abstract conceptualisation in schizophrenia. Psychological Bulletin, 82, 120-127. 